\title{
Influence of leukotriene gene polymorphisms on chronic rhinosinusitis
}

\author{
Hasan Al-Shemari ${ }^{\dagger 1}$, Yohan Bossé ${ }^{\dagger 2,3,4}$, Thomas J Hudson 2,5, \\ Myrna Cabaluna ${ }^{1}$, Melanie Duval ${ }^{1}$, Mathieu Lemire ${ }^{2,5}$, Sophie Vallee- \\ Smedja ${ }^{6}$, Saul Frenkiel ${ }^{1}$ and Martin Desrosiers* ${ }^{* 1,6}$
}

\begin{abstract}
Address: ${ }^{1}$ Department of Otolaryngology-Head and Neck Surgery, McGill University, Montreal, QC, Canada, ${ }^{2}$ McGill University and Genome Quebec Innovation Centre, Montreal, QC, Canada, ${ }^{3}$ Centre de Recherche, Hôpital Laval, Institut Universitaire de Cardiologie et de Pneumologie de l'Université Laval, Québec, QC, Canada, ${ }^{4}$ Laval University Hospital Research Center (CRCHUL), Quebec, QC, Canada, ${ }^{5}$ Ontario Institute for Cancer Research, Toronto, ON, Canada and ' $D e p a r t m e n t$ of Otolaryngology-Head and Neck Surgery, Montreal University, Montreal, QC, Canada

Email: Hasan Al-Shemari - alshemari_q8@yahoo.ca; Yohan Bossé - yohan.bosse@crhl.ulaval.ca; Thomas J Hudson - tom.hudson@oicr.on.ca; Myrna Cabaluna - myrna.cabaluna@muhc.mcgill.ca; Melanie Duval - mduval9@po-box.mcgill.ca;

Mathieu Lemire - mathieu.lemire@oicr.on.ca; Sophie Vallee-Smedja - sophie_smejda@yahoo.ca; Saul Frenkiel - sfrenkie@ent.jgh.mcgill.ca;

Martin Desrosiers* - desrosiers_martin@hotmail.com

* Corresponding author †Equal contributors
\end{abstract}

Published: 26 March 2008

BMC Medical Genetics 2008, 9:21 doi:10.1 186/1471-2350-9-21

This article is available from: http://www.biomedcentral.com/I47|-2350/9/2 I

(c) 2008 Al-Shemari et al; licensee BioMed Central Ltd.

This is an Open Access article distributed under the terms of the Creative Commons Attribution License (http://creativecommons.org/licenses/by/2.0), which permits unrestricted use, distribution, and reproduction in any medium, provided the original work is properly cited.
Received: 9 November 2007

Accepted: 26 March 2008

\begin{abstract}
Background: Chronic rhinosinusitis (CRS) is increasingly viewed as an inflammatory condition of the sinonasal mucosa interacting with bacteria and/or fungi. However, factors conferring susceptibility to disease remain unknown. Advances in genomics offer powerful tools to explore this disorder. The goal of this study was to evaluate the effect of single nucleotide polymorphisms (SNP) on CRS in a panel of genes related to cysteinyl leukotriene metabolism.
\end{abstract}

Methods: Severe cases of CRS and postal code match controls were recruited prospectively. A total of 206 cases and 200 controls were available for the present study. Using a candidate gene approach, five genes related to cysteinyl leukotriene metabolism were assessed. For each gene, we selected the maximally informative set of common SNPs (tagSNPs) using the European-derived (CEU) HapMap dataset. These SNPs are in arachidonate 5-lipoxygenase (ALOX5), arachidonate 5lipoxygenase-activating protein (ALOX5AP), leukotriene C4 synthase (LTC4S), cysteinyl leukotriene receptor I (CYSLTRI) and cysteinyl leukotriene receptor 2 (CYSLTR2) genes.

Results: A total of 59 SNPs were genotyped to capture the common genetic variations within these genes. Three SNPs located within the ALOX5, CYSLTRI and ALOX5AP genes reached the nominal $p$-value threshold $(p<0.05)$ for association with CRS. However, none of these SNPs resist multiple testing adjustment.

Conclusion: While these initial results do not support that polymorphsims in genes assessed involved in the leukotriene pathways are contributing to the pathogenesis of CRS, this initial study was not powered to detect polymorphisms with relative risk of 2.0 or less, where we could expect many gene effects for complex diseases to occur. Thus, despite this lack of significant association noted in this study, we believe that validation with external populations and the use of betterpowered studies in the future may allow more conclusive findings. 


\section{Background}

Chronic rhinosinusitis (CRS) is a frequent and important chronic disease, which causes significant patient discomfort and morbidity. Patients with CRS report a significantly lower quality of life index in measures of bodily pain and social functioning than do patients with congestive heart failure, angina, chronic obstructive pulmonary disease, and back pain [1]. In health surveys, CRS affect more than $10 \%$ of individuals in western countries, with an overall direct cost of CRS in the United States annually estimated at $\$ 4.3$ billion $[2,3]$.

Despite the frequency of CRS and the costs associated with its care, there is limited knowledge about the initial development of disease. Our current conception of CRS is as of a chronic inflammation of the paranasal sinus membrane, which is colonised with nasal and exogenous bacteria that may contribute to the disorder. Histologically, CRS is characterized by an accumulation of inflammatory cells that are mainly eosinophils, with a neutrophilic infiltrate only during acute infections. Numerous pro-inflammatory cytokines and chemokines, both Th- 1 and Th- 2 profiles, are over expressed in CRS. These include IL-2, IL4, IL-5, IL-6, IL8, IL-13 and IL-16 [4].

Current knowledge of the disease is limited to that garnered by study of biopsy samples obtained from patients affected with well-established disease, with little information available on early events or environmental factors associated with development of disease. Genetic studies may thus offer a better insight into the pathogenesis of the disorder. Recently, the primary interest in genetics has changed from simple Mendelian diseases, for which genotypes of some gene are the cause of disease, to more complex diseases, for which genotypes of some set of genes together with environmental factors merely alter the probability that an individual gets the disease, although individual factors are typically insufficient to cause the disease outright [5].

Reports of familial clustering of CRS support a genetic basis for the disease [6-8]. The high prevalence of patients with CRS in well-defined genetic disorders such as cystic fibrosis (CF) and primary cilia dyskinesia (Kartagener's syndrome) also supports the concept that mutated genes play a role in the pathogenesis of the disease [9]. However, it is suspected that CRS generally encountered in clinical practice is due to a complex interaction of multiple genes rather than the single gene anomalies as observed in CF and Kartagener's syndrome. A polygenic model for nasal polyps was recently confirmed by segregation analysis [10]. The same study also confirms that nasal polyp is a highly heritable disease with heritability coefficients above $60 \%$. Interestingly, the quantitative contribution of genetic factors seems to be higher in young and recurrent patients $[6,10]$. A number of genetic association studies have been conducted to elucidate the genetic loci conferring risk of CRS with or without nasal polyposis. Significant difference in allele frequencies between patients and controls were observed for polymorphisms located in the HLA [11-14], CFTR [15], LTA [16], TGFB1 [17], IL1RN [18], and ADRB2 [19]. However, all these findings remain to be confirmed in larger populations.

It is possible that cysteinyl leukotrienes (cysLTs) may play a disease-regulating role in rhinosinusitis. CysLTs, described primarily as lipid mediators involved in pathogenesis of airway inflammation and related symptoms such as bronchoconstriction, mucus secretion, and airway hyperresponsiveness, are recognized now as important mediators of cell trafficking and innate immune responses [20]. CysLTs are synthesized through the lipoxygenase (LO) pathway of arachidonic acid metabolism. The LO pathway for synthesizing cysLTs has several steps, and distinct enzymes are involved in each steps, namely arachidonate 5-lipoxygenase (ALOX5), arachidonate 5lipoxygenase-activating protein (ALOX5AP or FLAP), and leukotriene C4 synthase (LTC4S) [21]. Effects at the cellular level are mediated via two G-protein coupled receptors termed cysteinyl leukotriene receptor 1 (CYSLTR1) and cysteinyl leukotriene receptor 2 (CYSLTR2) (Figure 1).

In this initial study, we propose to study the genes regulating the leukotriene pathway to identify potential polymorphisms involved in disease susceptibility. We hope that identification of genetic polymorphisms involved will lead to improved comprehension of disease pathogenesis, and may eventually lead to more effective treatment, screening, and prevention of CRS.

\section{Methods \\ Population}

210 individuals with severe CRS were prospectively recruited from three tertiary rhinology clinics from July 2005 to February 2006. Four were not included in the final analysis, as phenotypic questionnaires were incomplete, leaving 206 subjects for analysis. These were compared to 200 control subjects. The study was approved by the McGill University Health Centre ethics committee, and written informed consent was obtained from all participants.

Subjects with sever CRS were recruited from ongoing clinical activities, according to pre-established clinical criteria. Severe CRS was defined as 1) individuals with persistent signs and symptoms of CRS with one previous endoscopic sinus surgery for diagnosis of either chronic rhinosinusitis with or without sinonasal polyposis or recurrent acute sinusitis or 2) individuals with more than one surgery for these diagnoses, regardless of outcome. 


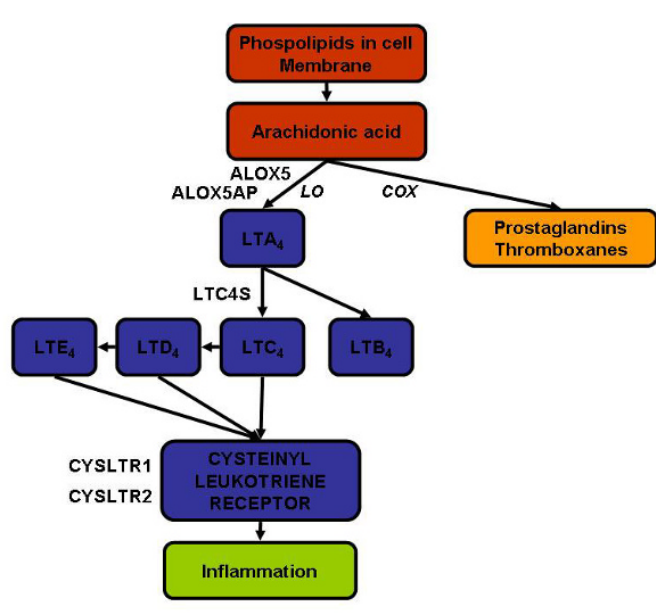

Figure I

Arachidonic acid metabolism. Candidate genes selected for genotyping are indicated along the cysteinyl leukotriene metabolic pathway. LO, lipoxygenase pathway; COX, cyclo-oxygenase pathway; ALOX5, arachidonate 5-lipoxygenase; ALOX5AP, arachidonate 5-lipoxygenase-activating protein; LTC4S, leukotriene C4 synthase; CYSLTRI, cysteinyl leukotriene receptor I; CYSLTR2, cysteinyl leukotriene receptor 2. Cysteinyl leukotriene metabolites are leukotriene B4 (LTB4), leukotriene C4 (LTC4), leukotriene D4 (LTD4), and leukotriene E4 (LTE4).

A standardized questionnaire assessing age, sex, ethnic origin, and family history was obtained. Other associated factors include smoking, presence of self-reported seasonal and perennial allergies, physician diagnosed asthma and acetylsalicylic acid intolerance were also obtained. Information on disease related factors including age at diagnosis, age at first surgery, number of previous surgeries, medications and current symptoms were determined. Initial diagnoses were obtained from patients records, and classified according to 2004 American Academy of Otolaryngology-Head and Neck Surgery (AAO-HNS) guidelines [22]. Diagnosis of aspirin sensitivity was based on a medical history reporting symptoms including asthma exacerbation, rhinorrhea, and nasal congestion, after the ingestion of aspirin or other nonsteroidal antiinflammatory drugs. Four tubes of blood were drawn from patients with severe CRS. Two were for DNA extraction and the others were for the measurements of serum eosinophilia and total IgE. Blood samples were stored at 20 degrees Celsius for 2 days then at -80 degrees Celsius prior to use.

The control population was recruited from either patient's spouse or non-blood relatives living in the same household or by random telephone screening matched to affected subject's postal code. For the 30 spouse or nonblood relative controls, whole blood was used. In the 170 control subjects recruited by telephone screening, the Oragene kit (DNA Genotek, Ottawa, Ontario) for saliva collection was sent to the control subject with prepaid return postage. Saliva samples were stored at room temperature as recommended by the manufacturer.

\section{IgE and eosinophilia measurements}

Blood samples for total serum IgE and eosinophilia were processed by the hospital laboratory according to standard methods. Eosinophilia was reported as percent of total circulating white blood cells. IgE was reported in IU, with the upper range of normal reported as $120 \mathrm{IU} / \mathrm{ml}$.

\section{DNA extraction}

DNA was isolated from peripheral blood leukocytes, collected in citrate-treated tubes, using the Puregene DNA isolation kit, (Gentra System, QIAGEN) following the High Throughput Protocol for $10 \mathrm{ml}$ Whole Blood provided with this kit. DNA extracted from saliva was performed using the Oragene DNA Purification Protocol (DNA Genotek, Ottawa, Ontario). Isolated DNA from both blood and saliva was stored at -20 degrees Celsius prior to use.

\section{SNP selection and genotyping}

SNPs were selected to capture as much information as possible about genetic variation for each gene. That was achieved using the European-derived (CEU) genotype data from the International HapMap project [23] covering ten kilobases up- and downstream of each gene. From this dataset, a maximally informative set of SNPs were selected for each gene using an aggressive tagging algorithm [24] implemented in Haploview version 3.2 [25]. Minor allele frequency and $\mathrm{r}^{2}$ thresholds were set at 0.05 and 0.8 , respectively. SNPs selected for each gene are shown in Table 1.

SNPs were genotyped using Sequenom matrix-assisted laser desorption/ionization time-of-flight (MALDI-TOF) mass array spectrometer (Sequenom, San Diego, CA). Primers were designed using the Sequenom SNP Assay Design software version 3.0 for iPLEX reactions. A total of 59 assays were designed within a 29-, 24- and 7-plexs reactions. The protocol and reaction conditions were in accordance with the manufacturer [26].

\section{Statistical analysis}

Sample size was designed to provide $95 \%$ power to detect common alleles (> 10\%) conferring a $>3.0$-fold increase in risk, and $50 \%$ power to detect alleles $>25 \%$ that increase risk by a factor of 2.0.

Hardy-Weinberg equilibrium (HWE) was estimated using a $\chi^{2}$ test. HWE tests were performed only in females for SNPs located on the X chromosome (SNPs located in the 
Table I: Association between single nucleotide polymorphisms in leukotriene pathway candidate genes and chronic rhinosinusitis.

\begin{tabular}{|c|c|c|c|c|c|c|}
\hline Gene (chr) & SNPs & MAF & Minor allele & HWE p value & Case, Control Ratios** & p value \\
\hline \multirow[t]{24}{*}{$\operatorname{ALOX5AP~(13)~}$} & rs 12430915 & 0.08 & C & 0.200 & $38: 378,26: 346$ & 0.271 \\
\hline & rs4769870 & 0.16 & $\mathrm{~T}$ & 0.080 & $353: 61,269: 61$ & 0.170 \\
\hline & rs 4076128 & 0.30 & C & 0.439 & 290:124, 255:11I & 0.909 \\
\hline & rsl1616333 & 0.05 & G & 0.558 & $22: 396,19: 353$ & 0.922 \\
\hline & rs4769055 & 0.33 & $A$ & 0.187 & $\mid 43: 275,120: 252$ & 0.561 \\
\hline & rs9578196 & 0.10 & $\mathrm{~T}$ & 0.408 & $380: 38,326: 42$ & 0.283 \\
\hline & rs4293222 & 0.37 & $\mathrm{C}$ & 0.930 & $161: 257,134: 236$ & 0.505 \\
\hline & rs 12429692 & 0.26 & $\mathrm{~T}$ & 1.000 & II8:300, 88:284 & 0.144 \\
\hline & rs10162089 & 0.49 & $\mathrm{~T}$ & 0.828 & $217: 197,184: 186$ & 0.453 \\
\hline & rs 4254165 & 0.28 & $\mathrm{C}$ & 0.928 & $302: 1 \mid 4,264: 108$ & 0.612 \\
\hline & rs4356336 & 0.42 & $\mathrm{C}$ & 1.000 & $242: 176,208: 154$ & 0.902 \\
\hline & rs 17612127 & 0.08 & $\mathrm{~T}$ & 0.847 & $40: 376,21: 343$ & 0.046 \\
\hline & rs 9506352 & 0.34 & $\mathrm{~T}$ & 0.300 & $278: 138,242: 128$ & 0.674 \\
\hline & rs9579648 & 0.15 & C & 0.317 & $68: 350,52: 320$ & 0.371 \\
\hline & rs9579649 & 0.07 & $\mathrm{~T}$ & 0.330 & $28: 388,24: 348$ & 0.875 \\
\hline & rs93।505I & 0.08 & $\mathrm{C}$ & 1.000 & $33: 385,26: 346$ & 0.629 \\
\hline & rs442037I & 0.25 & C & 0.842 & $107: 311,93: 277$ & 0.882 \\
\hline & rs 4466940 & 0.20 & $\mathrm{~T}$ & 0.295 & $85: 329,60: 256$ & 0.604 \\
\hline & rs9578200 & 0.17 & $\mathrm{~T}$ & 0.014 & $352: 66,307: 65$ & 0.525 \\
\hline & rs9285076 & 0.22 & $\mathrm{~T}$ & 0.133 & $326: 92,289: 83$ & 0.919 \\
\hline & rs9670198 & 0.04 & $A$ & 0.168 & $401: 15,329: 13$ & 0.887 \\
\hline & rs431960l & 0.41 & $\mathrm{~T}$ & 0.064 & $24 \mid: 163,209: 143$ & 0.938 \\
\hline & rs4769063 & 0.13 & $\mathrm{~T}$ & 1.000 & $365: 51,322: 50$ & 0.621 \\
\hline & rs4238139 & 0.28 & $\mathrm{C}$ & 0.028 & I|7:30|, 99:265 & 0.805 \\
\hline \multirow[t]{15}{*}{ ALOX5 (10) } & rs3824612 & 0.38 & $\mathrm{~T}$ & 0.263 & $273: 145,220: 152$ & 0.074 \\
\hline & rs3780894 & 0.17 & C & 0.789 & $85: 333,52: 320$ & 0.019 \\
\hline & rs7099684 & 0.19 & $A$ & 0.456 & $82: 332,65: 301$ & 0.466 \\
\hline & rs7919239 & 0.23 & $A$ & 0.392 & $101: 313,79: 293$ & 0.293 \\
\hline & rs2115819 & 0.47 & C & 0.414 & $195: 219,152: 180$ & 0.720 \\
\hline & rsII 239523 & 0.16 & $\mathrm{C}$ & 0.831 & $71: 345,55: 317$ & 0.383 \\
\hline & rs4948672 & 0.46 & C & 0.512 & $203: 215,161: 211$ & 0.137 \\
\hline & rs $1226480 \mid$ & 0.45 & $\mathrm{~T}$ & 0.028 & $230: 188,202: 168$ & 0.904 \\
\hline & rs378090I & 0.33 & $\mathrm{C}$ & 0.440 & |43:27I, I |6:250 & 0.400 \\
\hline & rs2279435 & 0.43 & C & 0.707 & $|87: 23|, \mid 56: 216$ & 0.428 \\
\hline & rsI565096 & 0.23 & $\mathrm{C}$ & 0.094 & $323: 95,283: 89$ & 0.691 \\
\hline & rs|487562 & 0.21 & $\mathrm{~T}$ & 0.381 & $97: 321,69: 301$ & 0.117 \\
\hline & rs229|427 & 0.30 & $\mathrm{~T}$ & 0.870 & 298:120, 257:115 & 0.498 \\
\hline & rs7393696 & 0.38 & $A$ & 0.394 & $256: 154,207: 135$ & 0.591 \\
\hline & rs7089063 & 0.24 & A & 0.478 & || $2: 304,61: 233$ & 0.059 \\
\hline \multirow[t]{11}{*}{ CYSLTR2 (13) } & rs2406939 & 0.36 & C & 0.948 & | $52: 266,130: 242$ & 0.678 \\
\hline & rsl1617224 & 0.11 & C & 1.000 & $375: 43,329: 4 \mid$ & 0.719 \\
\hline & rs6420296 & 0.08 & C & 1.000 & $389: 29,337: 33$ & 0.303 \\
\hline & rs7335898 & 0.06 & G & 0.790 & $28: 390,18: 336$ & 0.345 \\
\hline & rs9285169 & 0.09 & $\mathrm{~T}$ & 0.136 & $43: 373,26: 334$ & 0.129 \\
\hline & rs959596I & 0.48 & C & 0.994 & $203: 215,175: 195$ & 0.722 \\
\hline & rs 17072059 & 0.04 & $\mathrm{~T}$ & 0.784 & $407: 11,353: 17$ & 0.137 \\
\hline & rs7330127 & 0.44 & $A$ & 1.000 & 189:229, 155:207 & 0.501 \\
\hline & rs2407249 & 0.21 & C & 0.129 & $88: 330,74: 298$ & 0.687 \\
\hline & rs9568087 & 0.29 & A & 0.315 & $299: 117,254: 108$ & 0.600 \\
\hline & rs 12184704 & 0.07 & C & 0.057 & $33: 385,21: 339$ & 0.259 \\
\hline \multirow[t]{3}{*}{ CYSLTRI (X)* } & rs321090 & 0.23 & $\mathrm{C}$ & 0.605 & $247: 60,207: 81$ & 0.014 \\
\hline & rs321007 & 0.30 & $\mathrm{C}$ & 0.916 & $224: 84,192: 96$ & 0.107 \\
\hline & rs321006 & 0.13 & $\mathrm{~T}$ & 0.423 & $42: 266,37: 252$ & 0.764 \\
\hline \multirow[t]{3}{*}{ LTC4S (5) } & rs730012 & 0.29 & $\mathrm{C}$ & 0.403 & $126: 292,103: 269$ & 0.448 \\
\hline & rs2291418 & 0.04 & $\mathrm{~T}$ & 0.316 & $399: 15,347: 19$ & 0.284 \\
\hline & rsl66624 & 0.17 & $A$ & 1.000 & $77: 341,56: 316$ & 0.207 \\
\hline
\end{tabular}

HWE, Hardy-Weinberg equilibrium; MAF, minor allele frequency.

*Hardy-Weinberg and association tests were specifically calculated for the $X$ chromosome using the method implemented in Haploview 3.32

**Number of allele $A$ observed in cases : number of allele B observed in cases, number of allele $A$ observed in controls : number of allele $B$ observed in controls. 
CYSLTR1 gene). Case-control comparisons were analyzed using a $\chi^{2}$ test implemented in Haploview version 3.2 [25]. A nominal p-value less than 0.0012 was considered significant. This threshold was computed by permutation testing to ensure a project-wide type 1 error rate of 0.05 .

\section{Results}

210 patients with severe CRS were recruited. Four were not included in the analysis, as phenotypic questionnaires were incomplete. Table 2 shows the characteristics of cases and controls. For cases, initial diagnosis was recurrent rhinosinusitis in $12.1 \%$, CRS without polyposis in $13.1 \%$, and CRS with polyposis in $74.8 \%$. Average number of previous surgeries was 3.15 (range 1 - 20; median 2.0), with an average age at first surgery of 38.3 years (range $1-76$; median 38). Medication use in this group was high, with $73.4 \%$ of patients requiring medication beyond an inhaled nasal corticosteroid for disease control and $23.3 \%$ remaining uncontrolled despite medication. Atopy was present in $65.5 \%$ and asthma requiring treatment in $53.9 \%$. Active smoking was present in $11.2 \%$. Patients reported blood relatives affected with CRS in $37.7 \%$ of instances.

Measured serum biomarkers showed mean circulating eosinophilia of $4.4 \%$ (range 0 - 25\%; median $4.0 \%$ ) with $33.5 \%$ of patients demonstrating > 5\% eosinophilia. Mean total serum IgE was 155.9 IU (range 2 - 1460, median $=85.0$ ) with $41.1 \%$ having levels $\mathrm{IgE}>120 \mathrm{IU} / \mathrm{ml}$.

\section{Genetic analysis}

The assay conversion rate was 95\% (56 out of 59) and the average genotyping success rate for the 56 SNPs yielding working assays was 98.7\%. The remaining 3 SNPs (rs4503649, rs12561364 and rs1359112) failed the genotyping assay and were discarded from the analyses. All SNPs were in HWE, except rs9578200 where the p-value was 0.014 (Table 1).

Table 2: Characteristics of the subjects

\begin{tabular}{lcc}
\hline & Cases & Controls \\
\hline $\mathrm{n}$ Age (years) & 206 & 200 \\
Male: Female ratio & $52.3 \pm 13.0$ & $48.8 \pm 15.0$ \\
Ethnic group (\%) & 1.10 & 0.79 \\
$\quad$ White & & \\
Middle East & 85.2 & 89.5 \\
Jewish & 4.9 & 4.4 \\
Asian & 5.4 & 1.1 \\
First Nation & 1.5 & 1.1 \\
Black & 1.5 & 0.6 \\
Hispanic & 1.0 & 0.6 \\
Pacific Islander & 0.5 & 1.1 \\
\end{tabular}

Values are means \pm SD for age.
A final collection of 56 SNPs was tested for association. Figure 2 illustrates the location of each SNPs relative to the intron-exon structure of each gene. Figure 2 also depicts the genetic association results between SNPs and CRS. Three SNPs were found to be associated with CRS at a $\mathrm{p}$ value $<0.05$. These SNPs were found in the ALOX5 (rs3780894), ALOX5AP (rs17612127) and CYSTLR1 (rs321090) genes. However, none of these SNPs reached the multiple testing $\mathrm{p}$ value threshold of 0.0012 . The linkage disequilibrium pattern for each gene in our population is illustrated in Figure 3.

Spurious associations cause by population stratification is always a concern in genetic case-control association studies. Accordingly, the analyses were repeated with only White individuals (162 controls and 173 cases). Globally the results were very similar. All SNPs were in HWE and the minor allele frequencies were practically unchanged compared to all ethnicities included. The SNPs ALOX5rs3780894 and CYSLTR1-rs321090 remained statistically significant ( $\mathrm{p}=0.037$ and 0.031 , respectively). In contrast, SNP ALOX5AP-rs17612127 was no longer significant $(\mathrm{p}=$ $0.144)$.

\section{Discussion}

In this study, we have analyzed SNPs covering 5 genes implicated in the cysLT pathway in a case-control series of patients with severe CRS. After adjustment of multiple testing, there were no significant associations observed between severe CRS and genetic variants within these genes. Rather than suggest that there is no role for polymorphisms in the leukotriene cascade, it suggests that the effect of polymorphisms in cysLTs is less than the power detectable by our population size, which is well-powered to detect only polymorphisms in common alleles which confer a relative risk (RR) of 3.0 or greater, and only moderately powered to detect polymorphisms with a RR of 2.0. In this study, the minor allele of the most significant polymorphisms conferred a RR of 1.45 (ALOX5rs3780894), 1.67 (ALOX5AP-rs17612127) and 0.69 (CYSLTR1-rs321090). Most genes for complex diseases that have been described have an effect in this range or less.

Although SNP CYSLTR1-rs321090 is not significant after multiple testing correction, the results observed in the current study replicated the previous association reported by Hao et al [27]. In fact, the polymorphism, labeled 927T/C (rs320995) was significantly associated with atopy severity in a group of asthmatic families. Interestingly, this polymorphism is in tight linkage disequilibrium (LD) with rs321090 $\left(\mathrm{r}^{2}=0.82\right.$ based on the CEU genotyping dataset of the International HapMap project [23]). In both studies, the common allele is more frequent in cases than controls. In contrast, the current study does not corroborate 

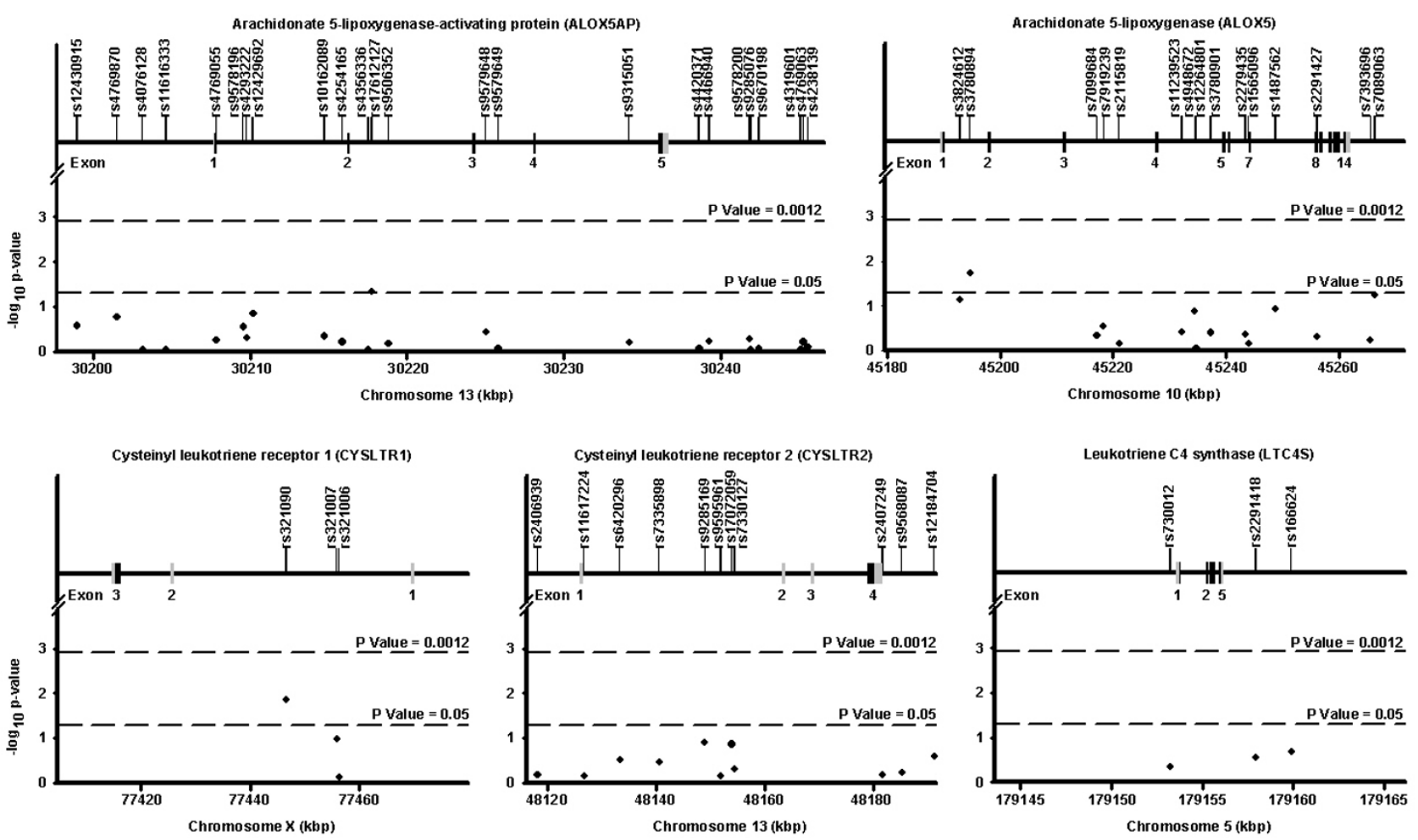

\section{Figure 2}

Genetic association of SNPs in the leukotriene pathway genes with chronic rhinosinusitis. Each subfigure presents the result of one gene. The top line indicates the gene name and symbol. The upper part of each subfigure shows the exon-intron structure of the gene and the localization of the genotyped SNPs. The coding exons are shown in black and the untranslated regions are shown in grey. The lower part of each subfigure illustrated the association results for chronic rhinosinusitis. The $\mathbf{x}$-axis shows the localization of the gene and SNPs on build 36. The $y$-axis shows the $p$ values on a log scale. The lower and upper dash lines represent $p$ value thresholds of 0.05 and 0.0012 , respectively. The gene structure for CYSLTR2 was taken from Fukai et al. [38]. The upper and lower parts of each subfigure are shown on the same scale.

the previous association between SNP LTC4S-rs730012 (also known as -444A/C) and allergic rhinitis [28]. However, a number of controversies exist concerning the role of this polymorphism in allergic-related diseases [29,30]. Accordingly, larger and well-powered studies will be required to determine the role of this polymorphism in pathogenesis of these diseases.

Beside the lack of power, other factors may explain the absence of significant results. First, we have studied what is a relatively heterogeneous population, with several different initial diagnoses, some unresponsive to therapy effective in others and different levels of serum biomarkers of inflammation. It is possible that the effect of cysLTs may be different within these groups and less noticeable in the group as a whole. Analysis of subgroups within our population may be of benefit but will be limited by sample size. Secondly, the control group utilized must also be considered. The group used has been selected for comparability in terms of environment rather than for absence of the disease. With the prevalence of self-reported chronic sinusitis being reported as high a $16 \%$ and the incidence of allergies being over $20 \%$, confusion with these other disorders may make it hard to differentiate from these other disorders.

Leukotrienes have nevertheless been implicated in CRS in other models and several studies have shown that leukotrienes may be involved in the development of the disorder. CysLT metabolites, leukotriene C4 (LTC4), leukotriene D4 (LTD4), and leukotriene E4 (LTE4) likely contribute to the pathogenesis of chronic rhinosinusitis through their effects on microvascular leakage, epithelial cell activation, elevated mucus secretion, and mucosal inflammation [31]. CysLTs also appear to be related to the severity of eosinophilic inflammation [32].

CysLTs appear related to nasal polyposis. In an examination of 27 patients by Kaplan et al. [33] patients with sinonasal polyps were noted by radioimmunoassay to have 

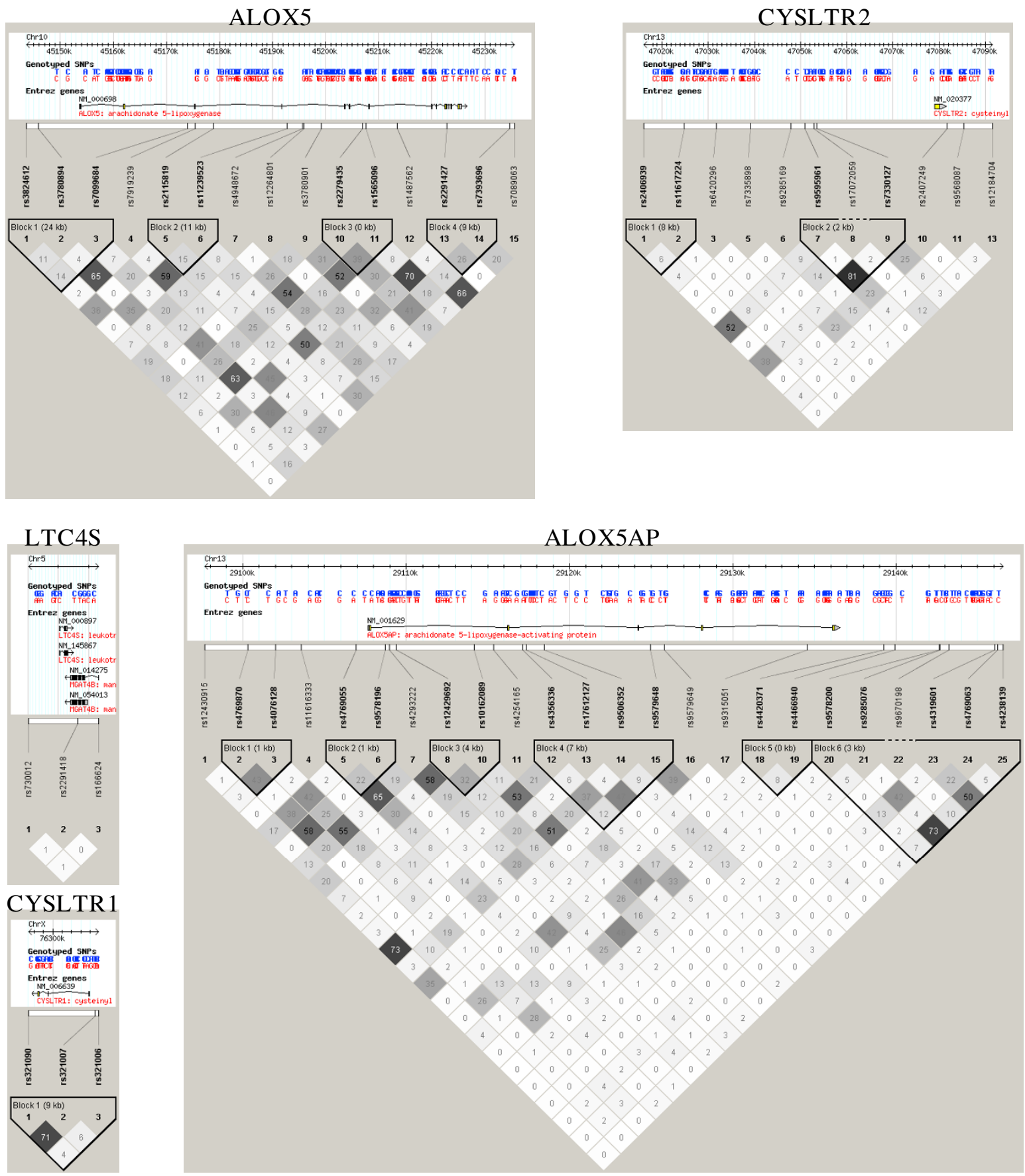

CYSLTR1

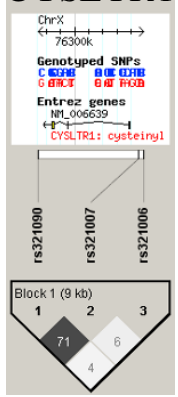

\section{Figure 3}

Linkage disequilibrium (LD) plots surrounding genes involved in the leukotriene pathway. The LD plots were generated by Haploview 3.32. [25]. Gene symbols are indicated at the top of each graph. The upper part of each graph illustrated the HapMap info track including the location of the gene on build 34. The white horizontal bar below the info track illustrated the location of SNPs on a physical scale. The color of squares illustrate the strength of pairwise $r^{2}$ values on a black and white scale where black indicates perfect LD $\left(r^{2}=1.00\right)$ and white indicates perfect equilibrium $\left(r^{2}=0\right)$. The $r^{2}$ LD value is also indicated within each square. Blocks are defined using the Gabriel et al. [39] definition. Failed and monomorphic SNPs as well as SNPs not in Hardy-Weinberg equilibrium are not illustrated. 
elevated levels of LTC4. Patients with sinonasal polyposis with recurrences within 18 months of surgery had higher levels of LTC4 when compared with those patients that did not have recurrences. In another study of 58 individuals, Steinke et al. [34] reported that chronic hyperplastic eosinophilic sinusitis is characterized by the increased presence of CysLTs when compared with concentrations seen in tissue from patients with chronic inflammatory sinusitis or healthy sinus tissue. Specifically implicating the polyp tissue as the source of these cysLTs, Higashi et al. [35] found that there were significant decreases in the urinary LTE4 concentrations before and after the sinus surgery for patients with chronic hyperplastic rhinosinusitis with nasal polyposis. In support of this, a recent study showed that urinary LTE4 concentration is highly significant in 10 patients with aspirin-intolerant asthma (AIA) with nasal polyps compare to patients with 24 AIA without polyps [36].

Despite the evidence supporting a role for leukotrienes other authors have failed to demonstrate a role for cysLTs in CRS. A study by Kountakis et al [37] showed that mean cysLTs levels were similar in CRS patients with eosinophilic versus non eosinophilic and in patients with polyps versus without polyp. Also cysLTs levels did not correlate with severity of CRS according to CT findings, endoscopy findings, or symptom scores.

\section{Conclusion}

While these initial results do not support that polymorphisms in genes assessed involved in the leukotriene pathways are contributing to the pathogenesis of CRS, this initial study was not powered to detect polymorphisms with relative risk of 2.0 or less, where we could expect many gene effects for complex diseases to occur. Thus, despite this lack of significant association noted in this study, we believe that validation with external populations and the use of better-powered studies in the future may allow more conclusive findings.

\section{List of abbreviations}

AIA: aspirin-intolerant asthma, ALOX5: arachidonate 5lipoxygenase, ALOX5AP: arachidonate 5-lipoxygenaseactivating protein, CF: cystic fibrosis, CRS: Chronic rhinosinusitis, COX: cyclo-oxygenase pathway, CYSLTR1: cysteinyl leukotriene receptor 1, CYSLTR2: cysteinyl leukotriene receptor 2, cysLTs: cysteinyl leukotrienes, HWE: Hardy-Weinberg equilibrium, LD: Linkage disequilibrium, LO: lipoxygenase pathway, LTB4: leukotriene B4, LTC4: leukotriene C4, LTC4S: leukotriene C4 synthase, LTE4: leukotriene E4, RR: relative risk, SNP: single nucleotide polymorphism

\section{Competing interests}

The author(s) declare that they have no competing interests.

\section{Authors' contributions}

HAS was involved in sample collection and draft the first version of the manuscript. YB carried out SNP selection and genotyping, performed statistical analyses, and finalized the manuscript. TJH participated in the design of the study. MC, MD, SVS, SF were involved in sample collection and coordination of the case-control population. ML calculated the p-value threshold to ensure a project-wide type 1 error rate of 0.05 . MD conceived the study, acquired the funding, and provided general supervision of the research group. All authors read and approved the final manuscript.

\section{Acknowledgements}

Y. Bossé was recipient of a fellowship award from the Canadian Institutes of Health and Research. T.J. Hudson was the recipient of a Clinician-Scientist Award in Translational Research by the Burroughs Wellcome Fund. Funding was provided by the Fondation Antoine Turmel, the Canadian Institutes of Health Research and the McGill Otolaryngology Head and Neck Surgery Research Fund.

\section{References}

I. Gliklich RE, Metson R: The health impact of chronic sinusitis in patients seeking otolaryngologic care. Otolaryngol Head Neck Surg 1995, I I 3(1): 104-109.

2. Bachert C, Hormann K, Mosges R, Rasp G, Riechelmann H, Muller R, Luckhaupt H, Stuck BA, Rudack C: An update on the diagnosis and treatment of sinusitis and nasal polyposis. Allergy 2003, 58(3): $|76-19|$.

3. Murphy MP, Fishman P, Short SO, Sullivan SD, Yueh B, Weymuller EA Jr: Health care utilization and cost among adults with chronic rhinosinusitis enrolled in a health maintenance organization. Otolaryngol Head Neck Surg 2002, I 27(5):367-376.

4. Desrosiers M: Refractory chronic rhinosinusitis: pathophysiology and management of chronic rhinosinusitis persisting after endoscopic sinus surgery. Current allergy and asthma reports 2004, 4(3):200-207.

5. Terwilliger JD, Goring $\mathrm{HH}$ : Gene mapping in the 20th and 2 I st centuries: statistical methods, data analysis, and experimental design. Human biology; an international record of research 2000, 72(I):63-I 32.

6. Cohen NA, Widelitz JS, Chiu AG, Palmer JN, Kennedy DW: Familial aggregation of sinonasal polyps correlates with severity of disease. Otolaryngol Head Neck Surg 2006, I34(4):60 I-604.

7. Drake-Lee A: Nasal polyps in identical twins. The Journal of Laryngology and Otology 1992, I06( I 2): 1 084-1085.

8. Greisner WA 3rd, Settipane GA: Hereditary factor for nasal polyps. Allergy Asthma Proc 1996, I 7(5):283-286.

9. Kaliner MA, Osguthorpe JD, Fireman P, Anon J, Georgitis J, Davis ML, Naclerio R, Kennedy D: Sinusitis: bench to bedside. Current findings, future directions. The Journal of Allergy and Clinical Immunology 1997, 99(6 Pt 3):S829-848.

10. Qu SH, Li TY, Li M, Shi JB, Wen WP, Wen WH: [Genetic epidemiologic study on nasal polyps]. Zhonghua Er Bi Yan Hou Tou Jing Wai Ke Za Zhi (Chinese Journal of Otorhinolaryngology Head and Neck Surgery) 2007, 42(8):608-6II.

II. Fajardo-Dolci G, Solorio-Abreu J, Romero-Alvarez JC, Zavaleta-Villa B, Cerezo-Camacho O, Jimenez-Lucio R, Olivo-Diaz A: DQAI and DQB I association and nasal polyposis. Otolaryngol Head Neck Surg 2006, I35(2):243-247.

12. Luxenberger W, Posch U, Berghold A, Hofmann T, Lang-Loidolt D: HLA patterns in patients with nasal polyposis. Eur Arch Otorhinolaryngol 2000, 257(3): I37-139. 
13. Molnar-Gabor E, Endreffy E, Rozsasi A: HLA-DRB I, -DQAI, and DQB I genotypes in patients with nasal polyposis. The Laryngoscope 2000, I I0(3 Pt I):422-425.

14. Zhai L, Sun Y, Tang L, Liu H: Polymorphism between loci for human leukocyte antigens $D R$ and $D Q$ in patients with nasal polyps. The Annals of otology, rhinology, and laryngology 2007, I I 6(I):66-68

15. Wang X, Moylan B, Leopold DA, Kim J, Rubenstein RC, Togias A, Proud D, Zeitlin PL, Cutting GR: Mutation in the gene responsible for cystic fibrosis and predisposition to chronic rhinosinusitis in the general population. Jama 2000, 284(14): $|8| 4-18 \mid 9$

16. Takeuchi K, Majima $Y$, Sakakura $Y$ : Tumor necrosis factor gene polymorphism in chronic sinusitis. The Laryngoscope 2000, IIO(I0 Pt I):|7|I-17|4.

17. Kim SH, Park HS, Holloway JW, Shin HD, Park CS: Association between a TGFbetal promoter polymorphism and rhinosinusitis in aspirin-intolerant asthmatic patients. Respir Med 2007, $101(3): 490-495$

18. Cheng YK, Lin CD, Chang WC, Hwang GY, Tsai SW, Wan L, Tsai $\mathrm{MH}$, Tsai J], Tsai FJ: Increased prevalence of interleukin-I receptor antagonist gene polymorphism in patients with chronic rhinosinusitis. Arch Otolaryngol Head Neck Surg 2006, I 32(3):285-290.

19. Bussu F, Tiziano FD, Giorgio A, Pinto AM, De Corso E, Angelozzi C, Brahe C, Paludetti G: Argl6gly polymorphism of the beta2adrenoceptor gene (ADRBeta2) as a susceptibility factor for nasal polyposis. American journal of rhinology 2007, 2 I (3):378-382.

20. Kanaoka Y, Boyce JA: Cysteinyl leukotrienes and their receptors: cellular distribution and function in immune and inflammatory responses. J Immunol 2004, I73(3): I503-15 I0.

21. Foegh ML, Hecker M, Ramwell PW: The eicosanoids: prostaglandins, thromboxanes, leukotrienes, and related compounds. In Basic and clinical pharmacology 5th edition. Edited by: Katzung BG. Connecticut: Appleton and Lange; 1998:304-318.

22. Meltzer EO, Hamilos DL, Hadley JA, Lanza DC, Marple BF, Nicklas RA, Bachert C, Baraniuk J, Baroody FM, Benninger MS, Brook I, Chowdhury BA, Druce HM, Durham S, Ferguson B, Gwaltney JM Jr, Kaliner M, Kennedy DW, Lund V, Naclerio R, Pawankar R, Piccirillo JF, Rohane P, Simon R, Slavin RG, Togias A, Wald ER, Zinreich S): Rhinosinusitis: Establishing definitions for clinical research and patient care. Otolaryngol Head Neck Surg 2004, I3 I(6 Suppl):SI-62.

23. A haplotype map of the human genome. Nature 2005 , 437(7063): $1299-1320$.

24. de Bakker PI, Yelensky R, Pe'er I, Gabriel SB, Daly MJ, Altshuler D: Efficiency and power in genetic association studies. Nature genetics 2005, 37(I I): | 2|7-| 223.

25. Barrett JC, Fry B, Maller J, Daly MJ: Haploview: analysis and visualization of LD and haplotype maps. Bioinformatics (Oxford, England) 2005, 2 I (2):263-265.

26. Oeth P, Beaulieu M, Park C, Kosman D, del Mistro G, van den Boom $D$, Jurinke C: iPLEX assay: Increased plexing efficiency and flexibility for MassArray system through single base primer extension with mass-modified terminators. SEQUENOM Application Note 2005

27. Hao L, Sayers I, Cakebread JA, Barton SJ, Beghe B, Holgate ST, Sampson AP, Holloway JW: The cysteinyl-leukotriene type I receptor polymorphism $927 \mathrm{~T} / \mathrm{C}$ is associated with atopy severity but not with asthma. Clin Exp Allergy 2006, 36(6):735-74I.

28. Eskandari HG, Unal M, Ozturk OG, Vayisoglu Y, Muslu N: Leukotriene $C 4$ synthase $A-444 C$ gene polymorphism in patients with allergic rhinitis. Otolaryngol Head Neck Surg 2006, I34(6):997-1000.

29. Isidoro-Garcia M, Davila I, Moreno E, Lorente F, Gonzalez-Sarmiento $R$ : Analysis of the leukotriene C4 synthase A-444C promoter polymorphism in a Spanish population. The Journal of allergy and clinical immunology 2005, I I 5(I):206-207.

30. Kedda MA, Shi J, Duffy D, Phelps S, Yang I, O'Hara K, Fong K, Thompson PJ: Characterization of two polymorphisms in the leukotriene C4 synthase gene in an Australian population of subjects with mild, moderate, and severe asthma. The Journal of allergy and clinical immunology 2004, I I 3(5):889-895.

31. Ueda T, Takeno S, Furukido K, Hirakawa K, Yajin K: Leukotriene receptor antagonist pranlukast suppresses eosinophil infiltration and cytokine production in human nasal mucosa of perennial allergic rhinitis. The Annals of otology, rhinology, and laryngology 2003, I I 2(I I):955-96I.

32. Perez-Novo CA, Watelet JB, Claeys C, Van Cauwenberge P, Bachert $\mathrm{C}$ : Prostaglandin, leukotriene, and lipoxin balance in chronic rhinosinusitis with and without nasal polyposis. The Journal of allergy and clinical immunology 2005, I I 5(6): I I89-I I 96.

33. Klapan I, Culo F, Culig J, Bukovec Z, Simovic S, Viseslav C, Risavi R, Zeljko B, Sprem N, Miljenko V: Arachidonic acid metabolites and sinonasal polyposis. I. Possible prognostic value. American journal of otolaryngology 1995, I6(6):396-402.

34. Steinke JW, Bradley D, Arango P, Crouse CD, Frierson H, Kountakis $\mathrm{SE}$, Kraft $M$, Borish L: Cysteinyl leukotriene expression in chronic hyperplastic sinusitis-nasal polyposis: importance to eosinophilia and asthma. The Journal of allergy and clinical immunology 2003, I I I(2):342-349.

35. Higashi N, Taniguchi M, Mita H, Kawagishi Y, Ishii T, Higashi A, Osame $\mathrm{M}$, Akiyama K: Clinical features of asthmatic patients with increased urinary leukotriene E4 excretion (hyperleukotrienuria): Involvement of chronic hyperplastic rhinosinusitis with nasal polyposis. The Journal of allergy and clinical immunology 2004, I I3(2):277-283

36. Micheletto C, Visconti M, Tognella S, Facchini FM, Dal Negro RW: Aspirin induced asthma (AIA) with nasal polyps has the highest basal LTE4 excretion: a study vs AIA without polyps, mild topic asthma, and normal controls. Allergie et Immunologie 2006, 38(I):20-23.

37. Kountakis SE, Arango P, Bradley D, Wade ZK, Borish L: Molecular and cellular staging for the severity of chronic rhinosinusitis. The Laryngoscope 2004, I I 4(I I): I895-1905.

38. Fukai $H$, Ogasawara $Y$, Migita O, Koga M, Ichikawa K, Shibasaki M, Arinami T, Noguchi E: Association between a polymorphism in cysteinyl leukotriene receptor 2 on chromosome $13 \mathrm{q} / 4$ and atopic asthma. Pharmacogenetics 2004, I 4(10):683-690.

39. Gabriel SB, Schaffner SF, Nguyen H, Moore JM, Roy J, Blumenstiel B, Higgins J, DeFelice M, Lochner A, Faggart M, Liu-Cordero SN, Rotimi C, Adeyemo A, Cooper R, Ward R, Lander ES, Daly MJ, Altshuler D: The structure of haplotype blocks in the human genome. Science 2002, 296(5576):2225-2229.

\section{Pre-publication history}

The pre-publication history for this paper can be accessed here:

\section{http://www.biomedcentral.com/1471-2350/9/21/prepub}

Publish with Bio Med Central and every scientist can read your work free of charge

"BioMed Central will be the most significant development for disseminating the results of biomedical research in our lifetime. "

Sir Paul Nurse, Cancer Research UK

Your research papers will be:

- available free of charge to the entire biomedical community

- peer reviewed and published immediately upon acceptance

- cited in PubMed and archived on PubMed Central

- yours - you keep the copyright 